on the one hand, allows the sun's rays to reach the earth during the day; and, on the other, allows the earth's heat to radiate rapidly into space at night.

In October invalids leave England's moist atmosphere, when the weather is already getting cold, and the evenings and mornings are foggy. The express train is often taken at Paris for Marseilles, and in sixteen or twenty hours the dry sunshiny Mediterranean region is reached. There it is still summer; the sun is powerful; the temperature high, usually above $70^{\circ}$ Fahr. The liver and skin, which were already in England relieved from the stimulus of our mild summer heat, are called violently and suddenly into action. The result is diarrboa, bilious attacks more or less severe, skin irritation, urticaria, boils, \&c. Diarrhca is so common that few northerners escape; and it is universally, and erroneously I believe, attributed to change of food, to wine, and to such influences.

These attacks are most severe with those who hurry their departure from England, push rapidly to their destination, and reach the south in September or early in Uctober. In my opinion the last week of October is quite early enough for invalids, or even healthy northerners, to arrive in the south of Europe. The cool weather of autumn does not begin until about the second week in November; and a month or six weeks of hot, oppressive southern weather, with a liberal allowance of mosquitoes, is generally damaging to the health of "north country people." The worst cases of bilious derangement that $I$ have to attend each autumn are amongst such.

By the end of April or the early days of May the sheltered Riviera undercliff begins to be disagreeably warm. Moreover, fine midsummer weather has been enjoyed so long that it becomes difficult to believe that winter still reigns in the north. 'The invalids are tired, also, of their sjx months' absence from home, and their hearts are set on the return. Once the home. ward journey has commenced it is generally rapidly carried on, and many arrive in Paris or in England early in May, much too soon for their own good. In the north of Europe, if the wind is from the south, in April and May the air is mild and balmy, and vegetation makes rapid strides; but until the mountain lands of Norway and Sweden are freed, or partly so, from their canopy of snow, which does not take place until June, a north. east wind brings cold, chilly weather and night frosts. It is this cold, chilly atmosphere, an atmosphere, too, more or less loaded with moisture, that often meets the invalid on his return home. The skin and liver, previously in full operation, are checked suddenly if the journey has been a rapid one, extra work is thrown on the lungs and kidneys, and very often severe attacks of influenza, of coryza, of bronchitis, of hæmoptysis, are the result.

I have pointed out the evil: I must now point out the remedy. It is to ignore the facilities afforded by express trains, and to make both the southern and the northern journeys in such a manner as to become acclimatized to the great changes.

Serions invalids who intend to winter in the south of Europe, are better out of England the last week in September, or early in October; but, as we have seen, their winter residence is scarcely fit for them before the end of October. The two, three, or four intervening weeks should be spent on the road. A quiet, leisurely progress southward allows the human econom to gradually accustom itself to the change of climate. A favourite station with me is Fontainbleau, thirty miles south of Paris. The climate is continental, drier than that of Eng. land, the hotels are good, and the forest scenery is very interesting and beautiful. A week or ten days may be spent there both pleasantly and profitably for health, much more so than in Paris.

Further south we have Valence, Aix Nimes, Arles, \&c. I would, however, more especially recommend a small watering place which I may nearly lay claim to have discovered, as far as my countrymen are concerned. It is Gréoulx, a five hours' picturesque drive from Aix-en.Provence. Greoulx is merely a village, with a large comfortable hotel, in its own grounds, erected over a hot sulphur spring, one of the most powerful and longest known thermal waters of the south of France. It celebrity, however, is all but entirely confined to that part of France. I myself found it out by the map, whilst trying to discover an autumn and spring intermediary station. I visited it last May, and was much pleased with the scenery from Aix, with the hotel and its grounds, and with the very lovely dis. trict in which it is situated. There are two wild mountain rivers-the Durance and one of its tributaries- within a mile of the house, and fishing and shooting are provided for the inmatus, with all the resources of French social country life. The hotel makes up some 200 beds. Gréoulx is quite out of the beaten track, fur away from railways, amongst the hills of Provence, and a residence there must have many charms. I sent a little colony of my Mentone friends and patients there this spring, and they were all delighted with it. There is an intelligent resident French physician, Dr. Jaubert. I do not think a pleasanter place could be found to spend a fortuight in on the way south.

'The same course can be followed by invalids on their return north. The departure from Mentone, Nice, Cannes, or from Italy or Spain, can take place at the end of A pril, or on the first day of May; and a leisurely journey may be made towards the north, so as to reach England by the end of May or the first day of June. Gréoulx is open on the 1st of May, and is even thus early very lovely; the deciduous trees in full leaf, and the nightingale in full song. A fortnight at Gréoulx, a week at Fontainbleau, and May is pleasantly consumed, and England and its climate reached by slow stages, which neatralize the risks attendant upon the "cannon-ball" style of travelling.

Grosvenor-street, August, 1863.

ON A

\section{METHOD OF OPERATING FOR RETENTION OF URINE IN CERTAIN CASES OF CANCER OF THE VULVA.}

By CHARLES H. MOORE, Esq., F.R.C.S., SURGEON TO THE MIDDLESEX HOSPITAL.

THE necessity of puncturing the bladder in women so seldom arises, that fow observations can be made upon the best method of performing that operation. I have been only twice called upon to relieve retention of urine by tapping the female bladder; yet, so far as I can learn, this is certainly not below the average number of cases in which the surgeons of the day have required to do so. In the male sex the operation is common enough in everyone's practice, and is by Mr. Cock's method very satisfactory.

There appear to be serious objections to the methods sug. gested for puncturing the bladder in women. The most pro. mising operation is that through the linea alba, and the most disappointing; for it, more than any other, is attended with the subsequent inconvenience, that an instrument can scarcely, and sometimes can not, be retained in the track of the punc. ture. The cause of this difficulty is twofold. On the one hand, as it is the function of the bladder to expel its contents, a catheter or a canula is at least as sure to be extruded as the natural contents of the organ; on the other hand, the channel of the puncture, thongh at first direct, becomes curved as the urine escapes. When the bladder is full, the apertures in the linea alba and the bladder correspond in situation. It is at this time that the puncture is made. But when the bladder contracts, the puncture in it descends far below that in the linea alba, and a tube, which is flexible enough to lie in both openings, is easily pushed out of the inner one by the bladder. Unless the tube zan be reintroduced, which is not always the case, the urine collects in the bladder again, or is infiltered in the tissues outside it.

To the operation of puncturing the bladder through the front wall of the vagina, an ample objection is supplied by every case of cancer or injury in which an unnatural communication is made between these parts. The irritation of the vagina by the urine is most distressing, and makes it improper for a surgeon purposely to establish such an opening. Moreover, in cases requiring the operation in question, it is most probable that the vagina itself will be obstructed by the disease, and not within reach for an operation.

To plunge a trocar and canula into the distended bladder through diseased structures in the perineum would present no difficulty in the mere operation, but would probably be attended with much trouble to the surgeon and pain to the patient in the subsequent management of the tube. Of the plan of punc. turing through the symphysis pubis I have no knowledge.

In the following case I adopted a method of operating which appeared to me likely to combine the advantages and avoid 
the disadvantages of the plans just reviewed. It afforded easy exit for the urine; it averted the liability of the tube to slip out of the bladder; it allowed of the syringing or irrigation of the bladder, which might become necessary; and it was capable of being continuously employed throughout the remainder of the patient's life.

A woman aged fifty has been under my care for some weeks in one of the Cancer wards of the Middlesex Hospital. She was admitted with a hard spherical tumour, as large as a middle-sized orange, springing from the ramus of the left pubes and ischium. None of the superticial structures in the perineum were connected with it, but the left half of the vulva was raised and spread over it. The orifice of the vagina was much narrowed, and the finger could scarcely be introduced into it. Neither could the os uteri be reached beyond the tumour, but the vagina was felt to be healthy. There was no ulceration of the tumour, and no disease of the inguinal glands. The tumour had first attracted attention by its swelling; it had not been noticed more than five months; it had grown rapidly, and had lately caused much pain, rendering it impossible for her to move about and attend to her duties. After some weeks the disease increased, and, the veins beneath the pubes being obstructed by it, the whole vulva became dusky and cedematous. The clitoris especially, and the nymphæ, enlarged and protruded; and the former grew hard, as if filled with cancerous matter. The suffering attending this state of the vulva was very great, and was not relieved by any ulceration of the swollen or the obstructing parts.

In the early stages of the case no inconvenience attended the act of micturition, but as the disease advanced it com pressed the meatus urinarius, and a difficulty began to be experienced in voiding the urine. This difficulty increased; the desire to pass urine was frequent and urgent; the quantity which escaped at each effort lessened ; at length a teaspoonful only was voided a few times a day, and no permanent relief was obtained even in the warm hip.bath. The bladder rose to the level of the umbilicus-a broad smooth rounded swelling, dull on percussion, and tender when touched. The countenance looked distressed, and its hue dark.

No relief could be afforded to the bladder by the use of the catheter. The meatus was hidden in the swollen parts, and their tender condition, together with the tight constriction of the urinary passage, precluded the use of instruments. As soon, therefore, as the obstruction had reached the degree which has just been described, and it was evident that no relief to the tension of the parts was about to be afforded by a spon. taneous sloughing of the tumour, I determined to puncture the bladder.

Having had chloroform administered, I introduced Mr. Cock's long curved trocar and canula about an inch above the pubes, and passed it through the linea alba into the bladder. With: drawing the trocar, I evacuated about half the urine, and relaxed the tension of the bladder. Then directing the canula behind the symphysis pubis, and pressing it, as nearly as I could judge, against the inner end of the meatus urinarius, I reintroduced the trocar into the canula, and pushed both through to the vulva. The relaxation of the bladder enabled me so far to depress the handle of the instrument against the abdomen that its point came out between the orifices of the vagina and the meatus. The bladder was thus transfixed. I then with. drew the trocar, and passed a string through the canula. To the lower end of the string I attached the point of a gum elastic catheter of the same size as the canula, and was thus enabled to pull both upwards together, and, as I withdrew the canula, to substitute the catheter for it in the double puncture. A cross piece of wood tied in front of the abdomen to the upper end of the catheter prevented it from slipping backward, and I found that when the wood was against the skin about one-half of the catheter projected below the vulva; but of course no urine escaped. It only remained to make a lateral opening at about the middle of the catheter in the part nearest the vulva, through which the urine might flow when that part of the instrument was pulled far enough upward.

This arrangement was found to be both convenient and safe. Each end of the catheter was secured against withdrawal : the upper by the piece of wood, and the lower by the ivory ring of the catheter. The bladder being not simply punctured, but transfixed, its wall could slide up and down the catheter securely, but the instrument could not be thrust out of the cavity. And as to the evacuation of the urine, it was only necessary, after oiling the lower half of the catheter, to pull upon its upper end uncil the lateral hole made in its middle reached the vesical cavisy; the urine would then flow out through the lower end of the instrument. When the bladder was emptied, and the upper end of the catheter oiled, traction on the lower end of it brought the hole out of the bladder, and no urine could flow through it.

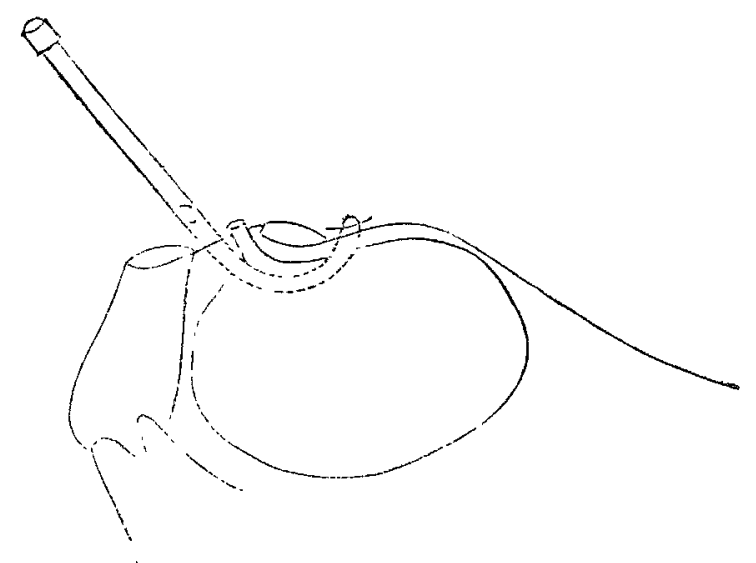

Sleep and freedom from pain followed the relief of the reten. tion. In a couple of days the dusky hue of the countenance had disappeared, and a little appetite returned. Some tenderness and swelling came on before the end of a week in the anterior part of the abdomen, a little to the right of the upper puncture, but both subsided in a few days. About a fortnight after the operation the upper track became too large for the catheter, and the urine welled up continuously by the side of it. Some pus, mucus, and a little urine escaped when the catheter was pulled up for the purpose of emptying the bladder. Fearing there might be inflammation of the bladder from the constant pressure of the instrument, I had a new catheter introduced, and the bladder frequently washed out with tepid water. As the catheter had three openings-one above, one in the bladder, and one below-the cleansing was very conveniently done by means of a syringe. The secretion of pus and mucus speedily ceased, and the patient from that time continued at ease, so far as micturition is concerned, and she suffered from the original disease considerably less than in the early period of the case.

Piccadilly, August, 1863.

\section{ON FRACT URES.}

Br W. H. B. WINCHESTER, EsQ., F.R.C.S.

THERE is no subject within the entire range of surgery on which so much has been written and yet so little real practical improvement made as that of fractures. A system so long and perseveringly followed as that on which the present treatment is based, but which has proved so barren of good results, mayreasonably be suspected of embracing some radical defect both of principle and practice. It will not be amiss, therefore, to examine one or two of its leading features, for the purpose of discovering the cause and its remedy.

In the first place, with regard to Extension. The views entertained respecting it are so erroneous, that until they are entirely abandoned no improvement can take place. Muscular contraction has been, and still is, the real bugbear. To counteract its supposed baneful influence, or in other words, to beep up permanent extension, has been the chief object sought to be attained, and no combination of forces the ingenuity of mechanicians could devise has been considered too powerful to attempt its accomplishment. Look, for instance, at the powerful screws attached to the extremities of some instruments-at the railway splint of Professor Dummreicher, some time since used in St. Bartholomew's Hospital, by which the lower part of the splint, supporting and holding in its grasp the lower or separated portion of the limb, is so contrived as to run away with it to the utmost limit of muscular elasticity. Such, too, is the effect of the practice of attaching a heavy weight to a cord from the foot, and letting it run over a pulley at the end of the bedstead. A similar result also follows the application of the most commonly used of all splints-viz., Desault's long splint, and of all ordinary forms of apparatus. Extension, therefore, as at present understood and practised by the above means, is a persistently active, and as such an iujurious, force. It can only be beneficial when temporarily employed to Ir 2 